\title{
Photophysics of Fullerenes: Thermionic Emission
}

\author{
R. N. Compton ${ }^{1,2}$, A. A. Tuinman ${ }^{1}$, and J. Huang ${ }^{3}$
}

1. The University of Tennessee. Knoxville. Tennessee 37996

2. Oak Ridge National Laboratory, Oak Ridge, Tennessee 37831-6125

3. Ames Laboratory, Iowa State University, Ames, Iowa 50011

TEOSED AUG 16 POกิ์

O S TI

\section{INTRODUCTION}

The high degree of symmetry and large number of endohedral and exohedral $\pi$-type electrons of the hollow cage fullerene molecule give rise to many interesting photophysical properties of this new allotrope of carbon. Of the many possible isomers of a given fullerene, those satisfying the rule that the twelve pentagons be isolated (i.e. do not share a bond) are the lowest in energy. The isolated pentagon rule (IPR) isomers are also the structures found to be most prevalent in the synthesis of fullerenes. Of the 1812 possible isomers of $C_{60}$ only the $I_{h}$ form is produced in the arc discharge or laser ablation method. Reminiscent of a Georges Seurat pointillism painting, $\mathrm{C}_{60}$ at a distance appears as a spherical "atom" of $\mathrm{K}_{\mathrm{h}}$ symmetry. Upon closer inspection the carbon atom "imperfections" give rise to the lower icosohedral symmetry of the cluster. The photophysical properties of $\mathrm{C}_{60}$ can be discussed by analogy to the "particle on a sphere" (see Savina et al. ${ }^{1}$ ). The energy levels for the $60 \pi$ electrons of $C_{60}$ occupying the degenerate levels representing "electrons on a sphere," along with the filling of empty orbitals in $I_{h}$ symmetry are shown below in Figure 1.
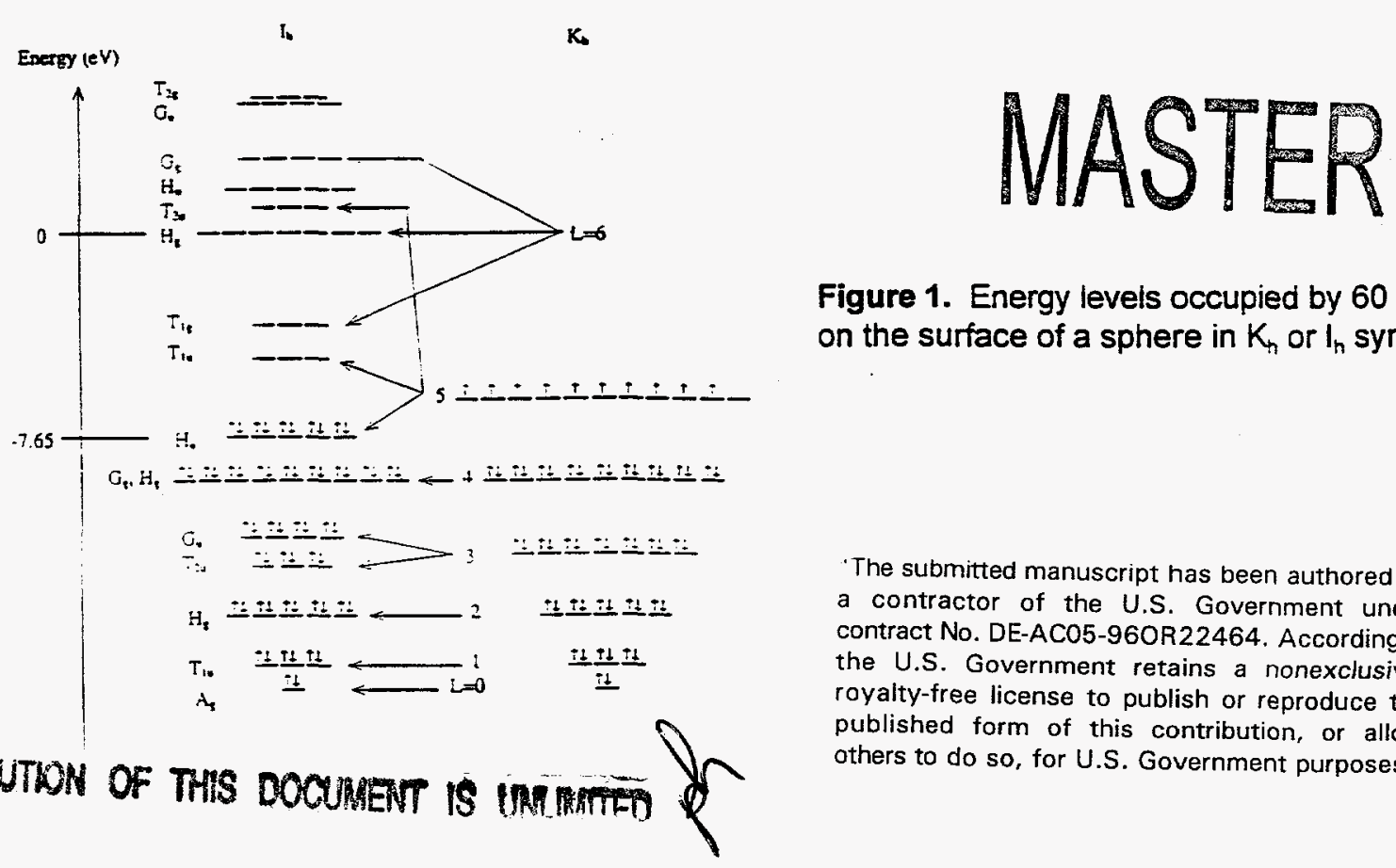

Figure 1. Energy leveis occupied by 60 electrons on the surface of a sphere in $K_{n}$ or $I_{n}$ symmetry.

\footnotetext{
-The submitted manuscript has been authored by a contractor of the U.S. Government under contract No. DE-AC05-960R22464. Accordingly, the U.S. Government retains a nonexclusive, royalty-free license to publish or reproduce the published form of this contribution, or allow athers to do so, for U.S. Government purposes."
} 


\section{DISCLAIMER}

This report was prepared as an account of work sponsored by an agency of the United States Government. Neither the United States Government nor any agency thereof, nor any of their employees, makes any warranty, express or implied, or assumes any legal liability or responsibility for the accuracy, completeness, or usefulness of any information, apparatus, product, or process disclosed, or represents that its use would not infringe privately owned rights. Reference herein to any specific commercial product, process, or service by trade name, trademark, manufacturer, or otherwise does not necessarily constitute or imply its endorsement, recommendation, or favoring by the United States Government or any agency thereof. The views and opinions of authors expressed herein do not necessarily state or reflect those of the United States Government or any agency thereof. 


\section{DISCLAIMER}

Portions of this document may be illegible in electronic image products. Images are produced from the best available original document. 
The energy level of the highest filled molecular orbital. $\mathrm{H}_{\mathrm{j}}$, is located at the known ionization potential of $\mathrm{C}_{50}$. Although the atomic $\left(\mathrm{K}_{\mathrm{h}}\right)$ particle on a sphere model provides a reasonable HOMO-LUMO, gap the known degeneracy of the HOMO (5-fold) and LUMO (3-fold) as well as the diamagnetism of $\mathrm{C}_{60}$ is accounted for by assuming $\mathrm{I}_{\mathrm{h}}$ symmetry, as inferred from single-line NMR and four-line IR spectra. The diamagnetism of $\mathrm{C}_{60}$ is driven by ring currents in the twelve isolated pentagons. ${ }^{2}$ Fullerene double bonds are more localized than that of a purely aromatic system. a property that governs its addition chemistry as well. Photoabsorption of most fullerenes occurs as a result of transitions in the UV since the high degree of symmetry renders the low-lying transitions to be forbidden. The beautiful purple color of most $\mathrm{C}_{60}$ solutions results from the lack of photoabsorption in the blue $(424-492 \mathrm{~nm})$ and red $(650 \mathrm{~nm})$ region of the spectrum. ${ }^{3}$ However, perturbations with the solvent and between fullerene solutes can make transitions more allowed and change the color of the solution greatly. Solvent effects on the optical limiting action of $\mathrm{C}_{60}$ solutions have been considered by Koudoumas et al. ${ }^{4}$

Photoabsorption in $\mathrm{C}_{60}$ is dominated by collective electronic motion, i.e. plasmons. Bertsch et al. ${ }^{5}$ predicted these Mie-type plasmons which have been observed in many experiments at $\sim 6 \mathrm{eV}(\pi$ plasmon) and $\sim 22 \mathrm{eV}$ ( $\pi$ plus $\sigma$ plasmon). Yoo et al. ${ }^{6}$ and Hertel et al. ${ }^{7}$ show a weak onset at the known ionization potential $\left(7.65 \mathrm{eV}\right.$ ) of $\mathrm{C}_{60}$ followed by a large peak in the cross section at $\sim 25 \mathrm{eV}$ which contains almost all of the expected oscillator strength (60). Although less well studied, plasmons may also strongly influence the electron impact ionization of $\mathrm{C}_{60}$. As shown in Figure 2, we find a weak intensity threshold in the cross section for electron impact ionization for $\mathrm{C}_{60}$ as well.

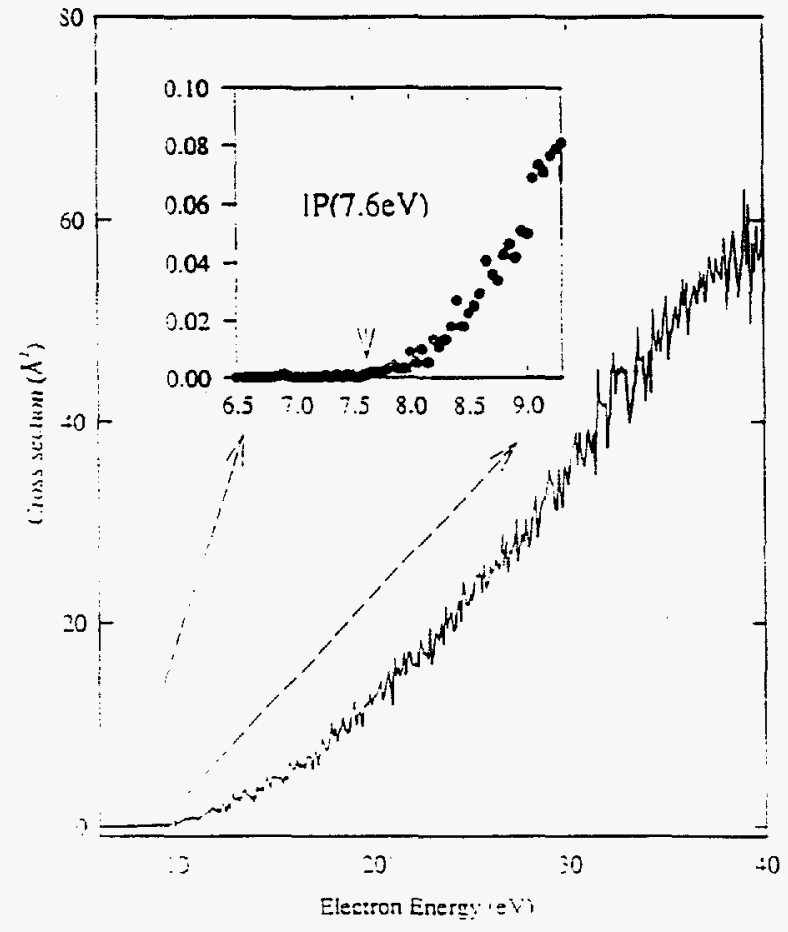

Figure 2. Relative cross section for the Electron impact ionization of $\mathrm{C}_{60}$. Notice the apparent delayed onset is actually a weak cross section at threshold. 
The energy scale for the high resolution electron beam ( hemispherical sector electron energy anaiyzer) was calibrated using the onset of argon ions at $15.76 \mathrm{eV}$. Thus the presence of the plasmon at $\sim 25 \mathrm{eV}$ appears to affect the appearance of the threshold for electron impact ionization of $\mathrm{C}_{60}$.

\section{Thermionic Emission}

Multiphoton ionization of fullerenes using long-pulse length $(>\mathrm{n} \mathrm{sec})$ lasers occurs mainly through vibrational autoionization. In many cases the laser ionization can be described as thermionic in analogy to the "boiling off" of electrons from a filament. Thermionic emission manifests itself as a "delayed" emission of electrons following pulsed laser excitation. The delayed emission of electrons for microseconds following multiphoton absorption of pulsed laser light has been reported for molecules. ${ }^{8}$ metal clusters ${ }^{7.10}$ fullerenes, ${ }^{11-15}$ and metcars. ${ }^{16}$ Klots ${ }^{17,18}$ has employed quasiequilbrium theory to calculate rate constants for thermionic emission from fullerenes which seem to quantitatively account for the observed delayed emission times and the measured electron energy distributions. ${ }^{16}$ The theory of Klots also accounts for the thermionic emission of $\mathrm{C}_{60}$ excited by a low power $\mathrm{CW}$ Argon Ion laser. ${ }^{19}$ Figure 3 summarizes the mechanism believed responsible for thermionic emission in fullerenes. The triplet state offers a pathway (ISC) to the "heat bath" of the $S_{o}$ ground electronic state.

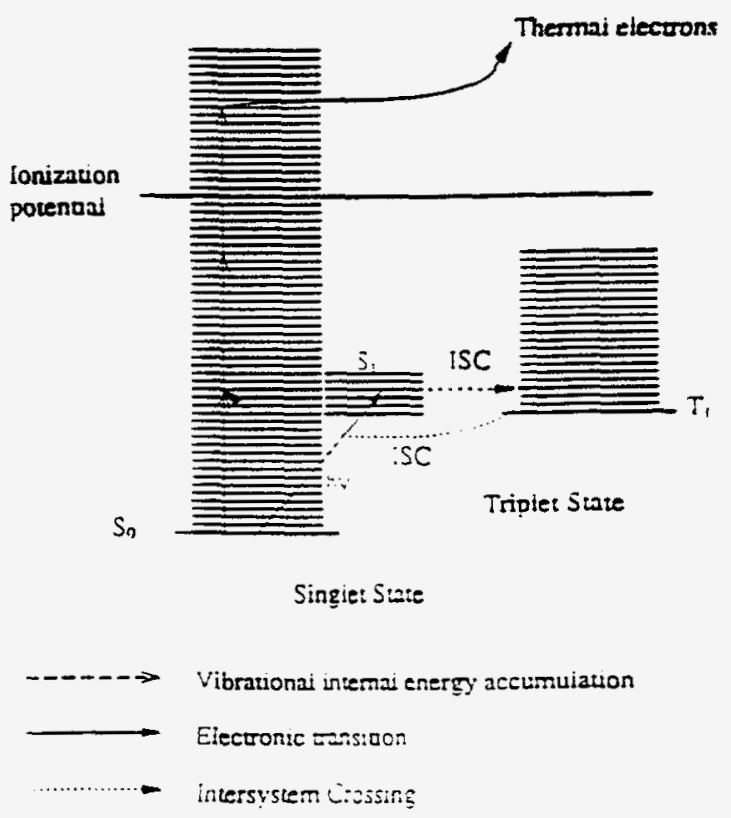

Figure 3. Mechanism leading to thermionic emission in $\mathrm{C}_{60}$. 
Recentiy Klots and Compton ${ }^{20}$ have reviewed the evidence for thermionic emission from small aggregates where mention was also made of experiments designed to determine the effects of externally applied electric fields on thermionic emission rates. Such effects are well characterized in bulk metals and semiconductors. We have measured the fullerene ion intensity as a function of the applied electric field and normalized this signal to that produced by single photon ionization of an atom in order to correct for all collection efficiency artifacts. Figure 4 shows a Schottky plot for the ion intensity ratio $\mathrm{C}_{60}{ }^{-} / \mathrm{Cs}^{+}$produced by $\mathrm{XeCl}$ pulsed laser light $(308 \mathrm{~nm}) .308 \mathrm{~nm}$ light efficiently ionizes cesium directly into the continuum, thus any variation in the $\mathrm{Cs}^{-}$ion signal with electric field should represent a collection efficiency change.

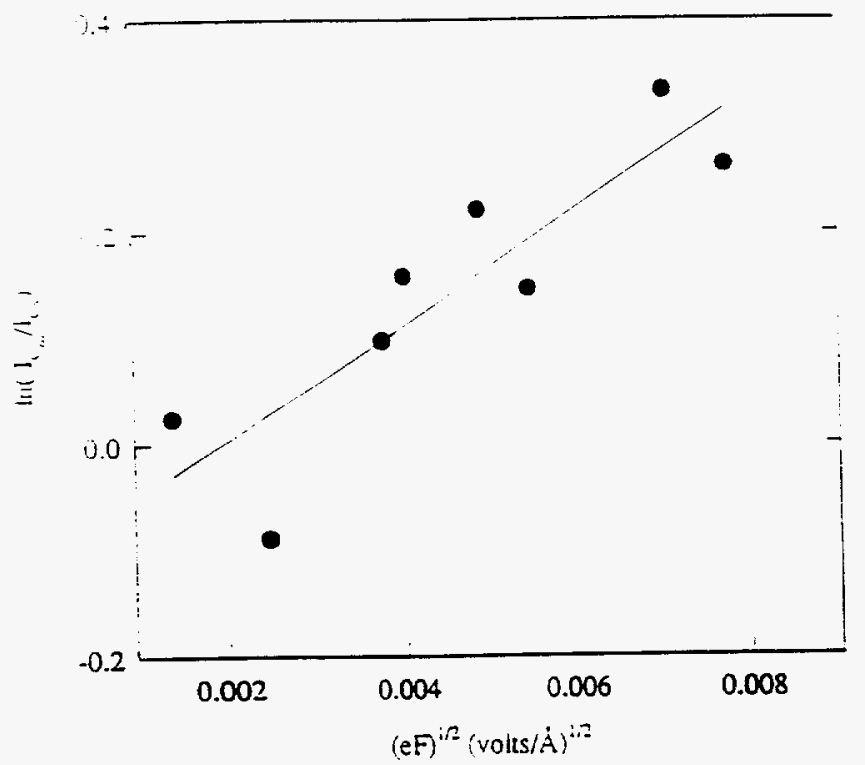

Figure 4. Shottky plot for field enhanced ionization of gas phase $\mathrm{C}_{50}$ at $308 \mathrm{~nm}$.

The increase in fullerene ion signal relative to that of $\mathrm{Cs}^{+}$is attributed to field enhanced thermionic emission. From the slope of the Schottky plot we obtain a temperature of approximately $1000 \mathrm{~K}$. This temperature is comparable to but smaller than that estimated from measurements of the electron kinetic energies $(\sim 1600-3700 \mathrm{~K})$. This result for field enhanced thermionic emission is discussed further by Klots and Compton."1

Thermionic emission from neutral clusters has long been known for autodetachment from highly excited negative ions. ${ }^{22}$ Similarly, electron attachment to $C_{60}$ in the energy range from 8 to $12 \mathrm{eV}$ resuits in $\mathrm{C}_{60}$ anions with lifetimes in the range of microseconds. ${ }^{23,24}$ Quasiequilibrium theory (QET) calculations $\mathrm{s}^{20}$ are in reasonable accord with these measurements. More recently we have observed the sequential attachment of two electrons to $\mathrm{C}_{84}$ in the gas phase, i.e., 


$$
e-C_{84}=C_{84}^{-*}
$$

Followed by

$$
e+C_{84}^{-*} \rightleftharpoons C_{84}^{=*}
$$

After mass selecting the metastable $\mathrm{C}_{84}{ }^{=* *}$ ion, we have observed its autodetachment into the $\mathrm{C}_{84}{ }^{-}$ anion. This is the first observation of the decay of a doubly-charged anion.

The observed magnitude of the $\mathrm{C}_{84}{ }^{-}$signal relative to that of $\mathrm{C}_{34}{ }^{-}$implies that the cross section for the attachment of the second electron is as large as that for attachment of the first electron. This is a surprising result since the long range interaction between the incident electron and $\mathrm{C}_{84}{ }^{-}$is repulsive. The capture of electrons into a state of high angular momentum might be facilitated by the excitation of vibrations (phonons) in the $\mathrm{C}_{84}{ }^{-}$anion. The possibility that of the formation of a "Cooper-pair" in the gas phase is intriguing. The fact that alkali atom doped $\mathrm{C}_{60}(3: 1)$ is a known superconductor strengthens this argument.

The two extra electrons in $\mathrm{C}_{84}{ }{ }$ are calculated to form a bound state (Mark Pederson, private communication). The dissociation of $\mathrm{C}_{84}{ }{ }$ into $\mathrm{C}_{84}{ }^{-}+\mathrm{e}$ is further inhibited by the presence of a Coulomb barrier (see Ref. 25). The decay of $\mathrm{C}_{84}{ }^{=*}$ into $\mathrm{C}_{84}{ }^{-}$over the top of the Coulomb barrier occurs mainly as a result of thermionic emission and from tunneling through the barrier to a much lesser extent. Again, the measured lifetime of $\mathrm{C}_{84}{ }^{=* *}$ can be accounted for by QET.

\section{ACKNOWLEDGMENTS}

Oak Ridge National Laboratory, managed by Lockheed Martin Energy Research Corporation for the U.S. Department of Energy under contract number DE-AC05-96OR22464. Research sponsored by the National Science Foundation CHE9508609 and the Office of Naval Research Molecular Design Institute through the Georgia Institute of Technology. Discussions with Joe Macek and Eph Klots are gratefully acknowledged.

\section{REFERENCES}

1. Savina, M. R., Lohr, L. L., Francis, A. H., Chem. Phys. Lett. 205, 200 (1993).

2. Zanasi, R., and Fowler, P. W., Chem. Phys. Lett. 238, 270 (1995).

3. Catalan. et al.. J., Angew. Chem. Int. Ed. Engl. 34, 105 (1995).

4. Koudoumas. E., Ruth, A. A., Couris, S., and Leach, S., Molecular Physics 88, 125-133 (1996).

5. Bertsch, G. F., Bulgac, A., Tomanek, D., and Wang, Y., Phys. Rev. Lett. 67, 2690 (1991).

6. Yoo, R. K., Ruscic, B., and Berkowitz, J., J. Chem. Phys. 96, 911 (1992). 
7. De Varies. J.. Steger, H.. Kamke. B., Menzel. C., Weisser. B.. Kamke, W., and Hertel, I. V., Chem. Phys. Lett. 188, 159 (1992).

8. P. D. Dao and A. W. Castleman, Jr.. J. Chem. Phys. 84. 1434 (1986).

9. Neiman. G. C., Parks, E. K., Richtsmeier. S. C.. Liu, K., Pobo. L. G., and Riley, S. R., High Temp. Science 22.115 (1986).

10. Leisner. T., Athanassenas, K., Echt, O.. Kandler, O., Kreisie. D., and Rechnagel, E., Z. Phys. D. 24, 81 (1992).

11. Campiell. E. E. B., Ulmer, G., and Hertel. I. V., Phys. Rev. Lett. 67, 1986 (1991).

12. Wang, L.-S., Concieicao, J., Jin, C., and Smalley, R. E., Chem. Phys. Lett. 182, 5 (1991).

13. Amrein. A., Simpson. R., and Hackett, P., J. Chem. Phvs. 95, 1781 (1991).

14. Wurz. P., and Lykke, K. R., J. Chem. Phys. 95, 7008 (1991).

15. Ding, D., Compton, R. N., Haufler. R. E., and Klots, C. E., J. Phys. Chem. 97, 2500 (1993).

16. Cartier. S. F., May, B. D., and Castleman, Jr., A. W., J. Chem. Phvs. 104. 3423-3432 (1996).

17. Klots, C. E., Chem. Phys. Lett. 186, 73 (1991).

18. Klots. C. E., J. Chem. Phys. 100, 1035 (1994).

19. Ding, D., Huang, J., Compton, R. N., Klots, C. E., and Haufler, R. E., Phys. Rev. Lett. 73, 1084 (1994).

20. Klots. C. E., and Compton, R. N., Surface Science Letters and Review (in press).

21. Klots. C. E., and Compton, R. N., Phys. Rev. Lett. 76, 4092 (1996).

22. Compton, R. N., et al., J. Chem. Phys. 45, 4634 (1966).

23. Jaffke. et al.. T., Chem. Phys. Lett. 226, 213 (1994).

24. Huang. J., Carman. H.S., and Compton. R. N., J. Phys. Chem. 99, 1719 (1995).

25. Scheller. M. K., Compton, R. N., and Cederbaum, L. S., Science 270, 1160 (1995). 